\title{
Determining Factors of Country Development and Nondevelopment
}

\author{
Onialisoa Mirana Rakotoarivelo, Hanitriniaina Sammy Grégoire Ravelonirina
}

Department of Mathematics and Computer Science, Faculty of Sciences, University of Antananarivo, Antananarivo, Madagascar

\section{Email address:}

onialisoarakotoarivelo@yahoo.com (O. M. Rakotoarivelo), rhsammy@yahoo.fr (H. S. G. Ravelonirina)

\author{
To cite this article: \\ Onialisoa Mirana Rakotoarivelo, Hanitriniaina Sammy Grégoire Ravelonirina. Determining Factors of Country Development and \\ Nondevelopment. Pure and Applied Mathematics Journal. Vol. 6, No. 1, 2017, pp. 25-38. doi: 10.11648/j.pamj.20170601.14
}

Received: December 30, 2016; Accepted: January 14, 2017; Published: February 22, 2017

\begin{abstract}
In this paper, we study the state of a country with the determining factors of the development-nondevelopment. For doing so, we have seen that they have indicators and sub-indicators. And after having calculated the weight and value of each determining factor, we created a new index to measure a country's development.
\end{abstract}

Keywords: Determining Factors, Development and Nondevelopment Index, Development Level Ranking

\section{Introduction}

For several decades now, development has always been defined hand in hand with under-development and/or poverty and the subject of many research works by researchers, economists, sociologists, scientists and international organizations who have been striving to reduce on the one hand the rate of poverty and on the other hand to find ways to develop third-world countries. According to the French economist F. Perroux, the aspects of development of a country are social, technical, infrastructures, economic and cultural. He defends the idea that development concerns the structural and qualitative aspects of growth, cf. [24]. According to the South Commission Report in [3], development must be based on the own resources both human and material of a country. It is thus a process that is both human, political, economic and social. The Indian economist A. Sen supports the thesis that the development of a country especially concerns the freedom of everyone, cf. [29]. Although he is one of the initiators of the Human Development Index (HDI), freedom is not yet included in this index. In this work, we globally analyze the pair development-nondevelopment. For doing so, a new approach has been adopted in order to study this pair with determining factors. Ten in number, determining factors $f_{i} \in\{1, \ldots, 10\}$ are inevitable and essential tools for development (resp. nondevelopment) of a country. With its indicators and subindicators, they allow the assessment of the intrinsic links between development and nondevelopment. Then we will demonstrate that there are interactions between them and there is four different states of determining factors obtained by using whole majority and half of the indicators and subindicators. We can classify them according to their order of importance. To study with subtlety the aspects of development (resp. nondevelopment), we will partition the set of ten determining factors. We will create a new index after which we denote by, an index that measures both the level and quality of development of one country. Therefore, we can set a new world ranking that encompasses simultaneously the HDI, the GNP and the various indicators of not only economic but also social development. Finally, this approach will lead to the creation of a new type of regime which highlights the policy as a catalyst, economy as a direction vector and the human as the ultimate basis for development. For the next paper, we plan to synthesize the law of conservation of pair development-nondevelopment from these determining factors.

\section{Preliminary and Definitions}

Represented as being both a process and a state, the concept of development is constantly under construction, transformation, change or expansion. The more innovations emerge in practice and reality catches up with the theory, the more dimensions have been added to this concept during its evolution. The following historical background testifies to it:

Definitions (1) Economic development is a set of interrelated transformations that occur in the structure of an economy, and that are necessary for continued growth. 
These changes concern the composition of its demand, production and employment as well as the foreign trade and capital movements abroad. Taken together, these structural changes define the transition from a traditional economy to a modern one, cf. [9]. Economic development is also the enrichment of nations through foreign trade which allows a surplus in the trade balance through investment in economic activities with increasing returns, cf. [30].

Economic growth is the increase over a long period, the volume of production and the country's wealth. It is a quantitative process based on the development of production factors, mineral (deep mining) and energy (coal, oil, nuclear power,...) as well as on technical progress. The Economic growth is also the positive change in the production of market goods and services in an economy over a given period, usually a long period, cf. [15].

The growth is sustainable increase of an unit economic, simple or complex, made of structural changes and possibly system ones and accompanied by economic progress, in [25].

The main indicators of development and economic growth are: GDP (Gross Domestic Product), GNP (Gross National Product) and GNI (Gross National Income). To calculate the distribution according to the population, one divides the GDP or GNP by the number of people. And there is also PPP GDP which is the value of the sum of all goods and services produced in the country valued at prevailing prices in the United States.

Proposition (2) Any economic development involves social problems.

Proof. Let $P$ be a country. Suppose that in $P$ there is economic development. So all activities are carried out for the production in order to obtain profits. In other words, we always try to minimize expenses (i.e. the production cost including staff salaries) and maximize profits. Then there is the existence of human exploitation through the difficult working conditions and wages received by workforce who constitute the majority of workers. So we have a social inequality based on perceived income and working hours. Hence the existence of social problems.

Remarks (3) - GDP and GNP take into account the added value produced by a country no matter how you got these added values. In addition, it provides no information on the concentration and dispersion of wealth created on the population.

- Production and services in the informal sector are not taken into account when calculating GDP and GNP. Yet these activities generate significant added values especially in underdeveloped countries.

Proposition (4) The calculation of GDP in PPP terms differs from one country to another.

Proof. Indeed, the convertibility of the national currency of a country in US Dollar is variable. Some countries set this convertibility according to the interest of his country and therefore it is the State which fixes, others use the ICM (Interbank Currency Market). Thus, the way two currencies are converted varies from one country to another.
In short, economic development is a "production - profit capital" type of development.

To face up to critics of a development centered on the economy and to redress the weaknesses of measuring development by GDP, international institutions have developed new indicators and defined the Human Development measured by using the HDI or Human Development Index.

Definition (5) [2], [14] According to UNDP, "Human development is a process that leads to the expansion of the range of opportunities available to everyone and improving the quality of individual and social life of the person." Created in 1990 by two economists Amartya Sen (India) Nobel Prize in economics in 1993 and Mahbub ul Haq (Pakistan) to the United Nations Development Program (UNDP), Human Development Index is a summary measure of the human development. It measures the average level of human development achieved in a country in three basic dimensions: long and healthy life (measured by life expectancy at birth); knowledge (measured by the means years of schooling and expected years of schooling) and decent standard of living (assessed using GNI per capita PPP US Dollar). It represents the geometric mean of normalized index used to measure the level achieved in each dimension. The HDI value is obtained using the formula (used since 2011):

$$
\mathrm{IDH}=\sqrt[3]{I_{\text {ife }} \cdot I_{\text {knowledge }} \cdot I_{\text {living }}}
$$

Proposition (6) Given the social (health and education) and economic indicators of the HDI, all the qualitative and quantitative aspects of development are not included in this indicator.

Proof. Let the HDI be. Let's suppose that the qualitative aspects of development are viewed through environment, society and man. For the environment there is the quality of water, air and soil. For those of society we find freedom, equality, democracy, corruption and security. For man, there is health, employment, education and universal human right. First take the two social indicators of the HDI. Namely health, it measures only life expectancy at birth. Yet the health status of a country is not only summarizes to this indicator. Indeed, this state depends on access to medical care and services, and social protection. In addition an important determinant for health is also the rate of infant and maternal mortality at birth. But the HDI calculates only life expectancy, while its indicators are incomplete to measure other qualitative aspects of development. Then let's consider education, indicators are also incomplete. Its indicators only count the number of years that one can expect to continue his studies but it does not indicate one of the most important indicators which is the attendance and access to these studies. In addition, development is based on the advanced technology, research and innovation, but the HDI does not take them into account. One can also see that in the HDI there are no indicators to measure freedom, equality, security, democracy and corruption or even the 
human right. So we have a counterexample. Finally consider the GNI measured on PPP for the HDI defined above, its calculation is based on GDP. So it depends on production and added value. Yet the GDP does not account for the negative effects of production on the environment. So the environment is neglected. We also note that incomes from informal sectors are not collected, while this is a sector that generates an easier and faster income particularly in underdeveloped country. Thus all the qualitative and quantitative aspects of development are not taken into account in calculating the HDI.

Remarks (7) In the HDI, the calculation of the index dimensional is not uniform. Indeed, the same weight is used for all indicators as they are calculated in different ways and they do not have the same number of indicators. For education, as it is composed of two indicators, the calculation of its dimensional indicators is different from that of health. Similarly, the index of GNI in dimensional conversion method using the "natural logarithm" is not clear. The HDI is a human development indicator nonetheless it does not take into account the home quality of the majority of the population, number of unemployed, working conditions and the daily income of each of them and finally the state of freedom and equality of all citizens of the same country.

So this is a "health - education - production" type of development.

In the 1990s, a global problem emerged: "man's actions are destroying and deteriorating the environment". And we found the following facts: climate changes, pollution (air, sea, land), the disappearance of several plant and animal species as well as the considerable reduction of natural resources. Basically, our environment is gradually destroyed while development depends largely on the environment. Trying to catch up this neglect, a new dimension was again added to the development which is the environment, hence "Sustainable Development" is created.

Definition (8) Sustainable development is a type, a character of development that aims to harmonize the use and conservation of natural resources with economic and human activities while providing for future generations. It was then a development that will ensure the sustainability of human actions on the environment. It is also a challenge for every country in the world in the fight against global warming and to minimize damages of human actions on the environment (pollution, destruction and intensive exploitation of air, water and land) and to preserve global biodiversity. Gro Harlem Brundtland, the Norwegian Prime Minister (1987) defined it as: "a development that meets the needs of the present without compromising the ability of future generations to meet their own needs", cf. [17].

Proposition (9) Sustainable development does not admit any tags.

Proof. First international indicators (i.e. accepted by all countries) to measure it are nonexistent. However each country has its own indicators to measure it but these indicators depends on the environmental area that it wants to protect from human reach. And then there is no international institution that can put pressure on a country (resp. government, company) about the behavior and the decision to be adopted for the realization of sustainable development. Thus, a country (resp. government, company) polluter is never punished while the rest of the world will endure the effects from it.

Proposition (10) Sustainable development achievement is local.

Proof. Achieving this type of development and its implementation is not only the responsibility of each government, but of every investor, company, institution, association and individual citizens. So sustainable development fully relies on our behaviors, actions, programs and regulations. But the center of sustainable development is the environment and condition of the latter depends on human actions. This proves that sustainable development requires the will and participation of everyone.

Theorem (11) The local non-achievement of sustainable development involves destructive global effects.

Proof. By using Proposition (10) and by noting that humans live in the same world, shares the same ozone layer, oxygen and ecosystem, we get the result.

Thus, sustainable development is of the "space - time production" type.

Definitions (12)

(a). Development is the combination of mental and social changes of a population that makes it able to grow cumulatively and permanently its global and real product, see [24].

(b). Development is an integrated process of political and economic which combines good governance and public participation, investment in human resources, trust in the operation of market forces, concern for the environment and the existence of a dynamical private sector, $\mathrm{cf}$. [1].

The concept of "underdeveloped country" is used for the first time by US President Harry Truman in 1949, during his speech on the State of the Union ("Point IV"). It justifies the aid to be given by rich countries to poor ones to stem the rise of communism.

Definitions (13)

(a). Underdevelopment is defined as the delay takeoff by five stages: the traditional state, the transition state to take off, the state of the startup, the state of maturation and the state of high mass consumption, cf. [27].

(b). Underdevelopment appears by specific structural characteristics and refers to three of them: inequality of the labor production and of the distribution of national income, the dislocation of economies and the domination of developed countries, cf. [4].

(c). Underdevelopment is not a cyclical phenomenon, lateness but a structural phenomenon, see [8].

So from these three different definitions, we can deduce that underdevelopment is the situation of a country that is neither capitalist nor communist. It results from the internal situation of a country conditioned by the international economic context. 
Definition (14) [16] As defined by the World Bank, poverty is the lack of socially acceptable standard of living or the inability to reach it. It is also the deprivation or lack of access to goods (consumption, production), services (education, health, credit) and fundamental rights (work, leisure...) beyond the only low income monetary. We distinguish absolute poverty considered at the level of a person from relative poverty (people are considered in comparison with other people).

In the following, the determining factors appoint the determining factors of development/nondevelopment.

\section{Determining Factors}

Given the Definition (12), we found that the development is multi-dimensional. Indeed, its realization depends not just on economic growth, but also and especially on the policy, the established sociocultural context and quality of the environment. It was noted then that the process and maintaining the development of a country is based on TEN (10) determining factors. From them, we can, on the one hand, develop a country regardless of its history, past, geographical, political and economic situation. And on the other hand, these determining factors also allow an already developed country to maintain its status and even improve it. Let's then define what "determining factors" are.

Definition (15) A determining factor is a sector and/or pillar area of the development as well as of the nondevelopment of a country. They are TEN (10): Agriculture, International Trade, Culture, Economy, Education, Employment, Industrialization, Infrastructures, Politics, Health.

All ten factors form a fundamental basis for development and nondevelopment.

Definition (16) The indicators of a determining factor are the components of each factor.

Definition (17) The sub-indicators of a determining factor are the components that define one or more indicator (s) of this factor.

Remarks (18) Indicators and sub-indicators are tools to measure development (resp. nondevelopment) of a given country.

The realization and fulfillment (resp. non-fulfillment) of indicators and sub-indicators for each factor allows takeoff of development (resp. the stationary and nondevelopment state) of a country.

Now then, let's enumerate one by one the ten determining factors along with their respective indicators and/or subindicators.

\subsection{Agriculture}

Agriculture is mainly composed of three (3) indicators which are followed by several sub-indicators:

a) Productivity (PO): ratio between consumption and production (rb), industrialization's foundation (if), yield per ha (yp)

b) Overproduction (OV): exportation (ex), transformation (tr)

c) Technique (TE): tools and materials (tm), technologies (te) (fertilizers, improved varieties and seeds...)

\subsection{International Trade}

International trade has only three (3) indicators:

a) Natural Resources (NR)

b) Market (MA)

c) Service (SE)

d) Trade balance (TB)

\subsection{Culture}

Culture has three (3) indicators that are composed in turn by several sub-indicators respectively:

a) Cultural Identity (CI) (viewed at the country level): traditions $(\mathrm{td})$, customs and manners $(\mathrm{cm})$, moral values $(\mathrm{mv})$, traditionality - modernity ( $\mathrm{tm})$

b) Equity, Equality and Liberty (EE) (seen at the society level): human rights (hr), distribution of wealth (dw), freedoms (fr), equality (eq), social contracts (sc)

c) Ideology (ID) (seen at the individual level): patriotism (pa), nationalism (na), citizenship (cz)

\subsection{Economy}

Economy is characterized by five (5) indicators which two (2) only have a few sub-indicators:

a) Monetary stability (MS): exchange rate (er), financial security (fs)

b) Degree of trade openness (DO): Regional (rg), Continental (ct), International (it)

c) Protectionism (PR)

d) GDP (economic activity) (GD)

e) Number of SMEs (Small and Medium Enterprise), SMIs (Small and Medium Industry) compared to informal sectors (NS)

\subsection{Education}

Education is characterized by five (5) indicators which have sub-indicators:

a) Basic Education (BE): attendance rate (ar), dropout rate (dr), accessibility (ac), adult literacy rate (al)

b) Secondary Education (SE): attendance rate (ad), existence of different orientations (scientific, literary, technical and professional) (do)

c) Higher Education (HE): production rate (tp), priority to scientific and technical fields (ps)

d) Scientific Research Promoting (SR): advancement of research laboratories (av), involvement rate of 4P (Partner, Public, Private and People) (iv), national research policy (nr)

e) Technical Progress (TP): use of new technologies (un), innovation (nn)

\subsection{Employment}

Employment has four (4) indicators and no sub-indicator: a) Unemployment rate (UR) 
b) Underemployment (UE)

c) Predominance of middle class (PM)

d) Residents living level (GNI per capita) (RL)

\subsection{Industrialization}

Industrialization is formed by three (3) indicators and nine (9) sub-indicators:

a) Productivity (PD): local and/or national market (ln), exportation (ep)

b) Means of Production (MP): raw materials (rm), skilled workforce and robotics (sw), investment (in) (public and private)

c) Competitiveness of different industries (DC): food and pharmaceutical (fp), heavy (hv), textiles (tx), technology (th)

\subsection{Infrastructures}

Infrastructures are composed by three (3) indicators and some sub-indicators:

a) Public Infrastructures (PI): transport (ts), energy (en), telecommunications (tl), public infrastructures $(\mathrm{pu})$

b) Decent Housing (DH): ratio between the number of inhabitants and living area (nl), quality of the living space (qh)

c) Urbanization (UB): urban plan (up), maintenance (mt), cleaning and/or sanitation (cs)

\subsection{Politics}

Politics has two (2) major indicators which all have their own sub-indicators:

a) Internal Policy (IP): good governance (gg), rule of law (rl), political stability (ps), corruption (cu), transparency (tc), fundamentalist (fd)

b) External Policy (EP): national sovereignty (ns), FDI (Foreign Direct Investment) (fd), strong diplomacy (sd)

\subsection{Health}

Health is composed by four (4) indicators and only one (1) has three (3) sub-indicators:

a) Demography (DG): life expectancy (le), fertility (ft), rates of infant and maternal mortality (im)

b) Nutrition (NU)

c) Welfare (WE)

d) Medical infrastructures (MI)

\section{Recalls on Measure Theory}

In the following, let $X$ be a non-empty set. We denote $\mathcal{P}(X)$ the set of all subsets of $X$. A collection of parts of $X$ is a subset of $\mathcal{P}(X)$ (so element of $\mathcal{P}(\mathcal{P}(X)$ ), see [7].

Definition (19) (Algebra). A collection A of subset $X$ is said to be algebra in $X$ if $A$ has the following properties

(i) $X \in \mathrm{A}$

(ii) for all $A \in \mathrm{A}$ implies $A^{c} \in \mathrm{A}$, where $A^{c}$ is the complement of $A$ relative to $X$,

(iii) if $A, B \in \mathrm{A}$ then $A \cup B \in \mathrm{A}$.

Definition (20) ( $\sigma$-Algebra). A collection $M$ of subset of $X$

is said to be $\sigma$-algebra in $X$ if $M$ is an algebra with the following property:

If $A_{n} \in M$ for all $n \in \mathbb{N}^{*}$, then $\bigcup_{j=n}^{+\infty} A_{n} \in M$

Terminology: If $M$ is a $\sigma$-algebra in $X,(X, M)$ is called a measurable space and the members of $M$ are called measurable sets.

Definition (21) (Content). [31] Let A be an algebra of subset of $X$.

A function $\mu: A \rightarrow[0,+\infty]$ is called a content if

(a). $\mu(\varnothing)=0$,

(b). $\mu(A \cup B)=\mu(A)+\mu(B)$ if $A, B \in \mathrm{A}$ and $A \cap B \in \mathrm{A}$.

Definition (22) (Measure). [6] If $(X, M)$ is a measurable space a content $\mu$ defined on the $\sigma$-algebra $M$ is called a positive measure if it has the following property: for any disjoint denumerable collection $\left(A_{n}\right)_{n \in \mathbb{N}^{*}}$ of members of $M$, $\mu\left(\bigcup_{j=n}^{\infty} A_{n}\right)=\sum_{n=1}^{\infty} \mu\left(A_{n}\right)$.

Terminology: If $(X, M)$ is a measurable space and the function $\mu: A \rightarrow[0,+\infty]$ is a positive measure, $(X, M, \mu)$ is called a positive measure space.

Proposition (23)

If $\mu_{f}(B)=\sum_{x \in B} f(x)$ for all $\mathrm{B} \in \mathrm{B}$, then $\mu_{f}(B)=$ $\sum_{x \in \mathbb{N}} f(x) \delta_{x}(B)$, where $\delta_{x}$ is the Dirac measure such that

$$
\delta_{x}=\left\{\begin{array}{l}
1, \text { if } x \in B \\
0, \text { if } x \notin B
\end{array}\right.
$$

\section{Proof. Cf. [7].}

Proposition (24) [6] Let $(\mathrm{X}, B)$ be a measurable space such that for all $x \in X,\{x\} \in B$. Consider $f: X \rightarrow[0,+\infty]$. Thus the map $\mu_{f}$ defines on $B$ by $\mu_{f}(B)=\sum_{x \in B} f(x)$ is a positive measure on $B$. It is called counting measure of weight $\mathrm{f}$.

Proof. Cf. [7].

\section{Weight of Each Determining Factor}

Let us denote by $f_{i}, \mathrm{i} \in\{1, \ldots, 10\}$ such that

$f_{1}=$ agriculture;

$f_{2=}$ international trade;

$f_{3}=$ culture;

$f_{4}=$ economy

$f_{5}=$ education;

Now we use a measure for calculating the weight $p_{i}$, $i \in\{1, \ldots, 10\}$ of determining factors. Considering one determining factor as a set $x_{i}, i \in\{1, \ldots, 10\}$ such that its indicators and sub-indicators are its elements. This computation is made according to their category.

Definition (25) Depending on indicators and subindicators, there are three categories. They are determining factors composed by indicators: "without" sub-indicators, "with" sub-indicators, "with and without" sub-indicators.

In the following we take a map $f$ from $X$ to $\mathbb{R}_{+}$such that for all $B \subset X, f(B)=\operatorname{card}(B)$.

\section{1. $I^{\text {st }}$ Category: Determining Factors Composed by Indicators “Without" Sub-Indicators}

Determining factors in this category are: international 
trade $\left(f_{2}\right)$ and employment $\left(f_{6}\right)$.

For $f_{2}$,

$$
B_{2}=P\left(X_{2}\right)=
$$

$\{\varnothing,\{N R\},\{M A\},\{S E\},\{T B\},\{N R, M A\}$

$\{N R, S E\},\{R N, T B\},\{M A, S E\},\{M A, T B\},\{S E, T B\}$,

$\{N R, M A, S E\},\{N R, M A, T B\},\{M A, S E, T B\},\{S E, T B, N R\}$,

$\{N R, M A, S E, T B\}\}$. We take $B_{2}=\{N R, M A, S E, T B\}$. Therefore $\mu_{f}\left(B_{2}\right)=\operatorname{card}\left(B_{2}\right)$

$=\operatorname{card}(\{R N, M A, S E, B C\})=4$. Thus $p_{2}=4$.

With the same reasoning, we find $p_{6}=4$, for $f_{6}$. Indeed, taking $B_{6}=\{T C, P C, N H\}$, we have $\mu_{f}\left(B_{6}\right)=4$.

\section{2. $2^{\text {nd }}$ Category: Determining Factors Composed by Indicators "with"Sub-Indicators}

Here is the list of determining factors in this category: agriculture $\left(f_{1}\right)$, culture $\left(f_{3}\right)$, education $\left(f_{5}\right)$, industrialization $\left(f_{7}\right)$ and politics $\left(f_{9}\right)$.

Proposition (26) We consider

$X_{i}=\left\{x_{1}, \ldots, x_{i}\right\}$ such that $i \in I$ finite and $Y_{j}=\left\{y_{1}, \ldots, y_{j}\right\}$ where $j \in J$ finite, two non-empty sets. Let be $B_{x}=P(X)$ and the set $B_{y}=P(Y)$ their respective $\sigma$-algebra, with $X=\mathrm{U}_{i \in I} X_{i}$ and $Y=$ $\mathrm{U}_{j \in J} Y_{j}$. If $P(X) \cap P(Y)=\emptyset$, then $B_{X} \cup B_{Y}$ is a $\sigma$-algebra on $X \cup Y$ and $\left(X \cup Y, B_{X} \cup B_{Y}\right)$ is a measurable space.

Proof. This is a classical one. Indeed, let $\left(X_{i}, B_{i}=\left(P\left(X_{i}\right)\right)\right.$ and $\left(\left(Y_{j}, B_{j}=\left(P\left(Y_{j}\right)\right)\right.\right.$ are two measurable spaces where $i \in I$ $=\{1, \ldots, n\}$ and $j \in J=\{1, \ldots, m\}$, such that $I$ and $J$ are two non-empty sets, such that $B_{i} \cap B_{j}=\emptyset$. We prove that ( $(X$ $\left.\left.=\cup_{i \in I} X_{i}\right) \cup\left(Y=\cup_{j \in J} Y_{j}, B_{X} \cup B_{Y}\right)\right)$ is also a measurable space. We have $0 \in B_{i}$ et $0 \in B_{j}$ thus

$0 \in B_{i} \cup B_{j}$, therefore $0 \in B_{X} \cup B_{Y}$ and (i) is verified. Next, the union $x_{i}$ with $y_{j}$ such that $i \in I$ and $j \in J$ are in $B_{i} \cup B_{j}$. So the union of $x_{i}$ with $y_{j}$ is in $B_{X} \cup B_{Y}$ therefore, (ii) is verified. For all $x_{j} \in B_{i}$, its complement $x_{i}^{c}$ is in $B_{i}$. By the same way $y_{j} \in B_{j}$ implies $y_{j}^{c} \in B_{j}$ where $i \in I, j \in J$. As $B_{i} \cap B_{j}=\varnothing$, the union of $x_{i}^{c}$ with $y_{j}^{c}$ is an element of $B_{i} \cup B_{j}$. Hence the union of $x_{i}^{c}$ with $y_{j}^{c}$ is an element of $B_{X} \cup B_{Y}$. Thus $B_{i} \cup B_{j}$ is a $\sigma$-algebra on $X_{i} \cup Y_{j}$ for $i \in I$ and $j \in J$.

In this case, we consider indicator as the set $X$ and subindicators as its elements. Let's take agriculture $X_{1}$ which have three (3) indicators and (7) sub-indicators. Let be $X_{1}^{1}=P R \quad(P R$ appoints productivity which is the first indicator). So

$$
\begin{gathered}
B_{1}^{1}=P\left(X_{1}^{1}\right)= \\
\{\varnothing,\{r b\},\{i f\},\{y p\},\{r b, i f\},\{r b, y p\},\{i f, y p\},\{r b, i f, y p\}\} .
\end{gathered}
$$

We consider that $B_{1}^{1}=\{r b, i f, y p\}$ thus $\mu_{f}\left(B_{1}^{1}\right)=3$. Next, let $X_{1}^{2}=O V$ ( $O V$ refers to overproduction, the second indicator). So $B_{1}^{2}=P\left(X_{1}^{2}\right)=\{\varnothing,\{e x\},\{t r\},\{e x, \operatorname{tr}\}\}$. We take $B_{1}^{2}=\{e x, t r\}$ thus $\mu_{f}\left(B_{1}^{2}\right)=2$. For the third indicator $X_{1}^{3}=T E$, we use the same calculation. Thus $\mu_{f}\left(B_{1}^{3}\right)=2$. As $B_{1}^{1} \cap B_{1}^{2} \cap B_{1}^{3}=\varnothing$ so using the condition 2 in the Definition (21), we have: $\mu_{f}\left(B_{1}^{1} \cup B_{1}^{2} \cup B_{1}^{3}\right)=$ $\mu_{f}\left(B_{1}^{1}\right)+\mu_{f}\left(B_{1}^{2}\right)+\mu_{f}\left(B_{1}^{3}\right)=7$
Nevertheless $X_{1}=X_{1}^{1} \cup X_{1}^{2} \cup X_{1}^{3}$ with the $\sigma$-algebra $B_{1}^{1} \cup B_{1}^{2} \cup B_{1}^{3}$ is a measurable space according to Proposition (26). Then $\mu_{f}\left(X_{1}\right)=\mu_{f}\left(B_{1}^{1}\right)+\mu_{f}\left(B_{1}^{2}\right)+\mu_{f}\left(B_{1}^{3}\right)$ because $B_{1}^{1} \cap B_{1}^{2} \cap B_{1}^{3}=\varnothing$. Hence $\mu_{f}\left(X_{1}\right)=7=p_{1}$. Analogously, we find $p_{3}=11$ for culture $\left(f_{3}\right), p_{5}=13$ the weight of education $\left(f_{5}\right)$. Industrialization $\left(f_{7}\right)$ has a weight $p_{7}=9$, infrastructures $\left(f_{8}\right), p_{8}=9$ and politics $\left(f_{9}\right)$ weights $p_{9}=9$.

\section{3. $3^{\text {rd }}$ Category: Determining Factors Composed by Indicators "with and Without" Sub-Indicators}

It is economy $\left(f_{4}\right)$ and health $\left(f_{10}\right)$. The method of calculating the weight of these factors is in three steps:

- $1^{\text {st }}$ step: we group all indicators without sub-indicators in a set, then we determine the $\sigma$-algebra corresponding;

- $2^{\text {nd }}$ step: for indicators with sub-indicators, we adopt the same technique used in the $2^{\text {nd }}$ category;

- $3^{\text {rd }}$ step: we use Proposition (26).

Let us take the case of economy $\left(f_{4}\right)$.

$1^{\text {st }}$ step: as $\left(f_{4}\right)$. have three indicators without subindicators, pose $X_{4}^{1}=\{P R, G D, N S\}$

where $P R$ appoints to protectionism, $G D$ refers to GDP and $N S$ the number of SMEs, SMIs compared to informal sectors. Therefore

$$
\begin{gathered}
B_{4}^{1}=P\left(X_{4}^{1}\right)= \\
\{\varnothing,\{P R\},\{G D\},\{N S\},\{P R, G D\},\{P R, N S\},\{G D, N S\},\{P R, G D, N S\}\} .
\end{gathered}
$$

Consider $B_{4}^{1}=\{P R, G D, N S\}$ thus $\mu_{f}\left(B_{4}^{1}\right)=3$.

$2^{\text {nd }}$ step: $\left(f_{4}\right)$ gets also two indicators without subindicators which are SM (Monetary Stability) and DO (Degree of trade Openness).

For $S M, B_{4}^{2}=P\left(X_{4}^{2}\right)=\{\varnothing,\{e r\},\{f s\},\{e r, f s\}\}$ Let be $B_{4}^{2}=\{f t, s f\}$ so $\mu_{f}\left(B_{4}^{2}\right)=2$. For $D O, B_{4}^{3}=P\left(X_{4}^{3}\right)=$ $\{\varnothing,\{r g\},\{c t\},\{r g, c t\}\}$.

Let be $B_{4}^{3}=\{r g, c t\}$ so $\mu_{f}\left(B_{4}^{3}\right)=2$.

$3^{\text {rd }}$ step: As $X_{4}=X_{4}^{1} \cup X_{4}^{2} \cup X_{4}^{1}$ and $B_{4}=B_{4}^{1} \cup B_{4}^{2} \cup B_{4}^{1}$ is a $\sigma$-algebra of $X_{4}$ then we have $\mu_{f}\left(X_{4}\right)=\mu_{f}\left(B_{4}^{1}\right)+$ $\mu_{f}\left(B_{4}^{2}\right)+\mu_{f}\left(B_{4}^{1}\right)$ Hence $\mu_{f}\left(X_{4}\right)=7=p_{4}$.

Analogously we find $p_{10}=6$ the weight of health.

We resume in the following table the weight of every determining factor (cf. Table 1).

Table 1. Weight of determining factor.

\begin{tabular}{ll}
\hline Determining factor & Weight $\boldsymbol{p}_{\boldsymbol{i}}$ (total) \\
\hline Agriculture & $p_{1}=7$ \\
International trade & $p_{2}=4$ \\
Culture & $p_{3}=11$ \\
Economy & $p_{4}=7$ \\
Education & $p_{5}=13$ \\
Employment & $p_{6}=4$ \\
Industrialization & $p_{7}=9$ \\
Infrastructures & $p_{8}=9$ \\
Politics & $p_{9}=9$ \\
Health & $p_{10}=6$ \\
TOTAL & $p_{\text {total }}=76$ \\
\hline
\end{tabular}

Source: Author.

NB: The weight of the determining factors in the table above is their maximum weight. But according to the actual 
situation of each country and time (month or year), this weight varies. This is due to the economic, social, political and cultural life when each factor is evaluated according to its indicators and sub-indicators.

\section{Determining Factor's Value}

We adopt the following notations:

$\left\lfloor M_{i}\right\rfloor$ : the whole majority of $i^{t h}$ determining factor,

$\left\lfloor m_{i}\right\rfloor$ : the whole half of $i^{t h}$ determining factor,

$l_{i}$ : indicator's number $i^{\text {th }}$ determining factor,

$\alpha_{j}$ : the $j^{\text {th }}$ sub-indicator number of indicator.

Definitions (27) For $i \in\{1, \ldots, 10\}$ :

A determining factor $f_{i}$ is "very supportable" if at least $[80 \%]$ or the "whole majority" of its indicators is verified. So $p_{i}\left(\left|M_{i}\right|\right)<p_{i}<p_{i}$ (total).

A determining factor $f_{i}$ is said "supportable" if at least [50\%] or the "whole half" of its indicators is satisfied. Then we put a weight $p_{i}\left(\left|m_{i}\right|\right)<p_{i}<p_{i}\left(\left|M_{i}\right|\right)$.

A determining factor $f_{i}$ is said to be "unsupportable" if at most [50\%] of its indicators is not obtained. It is assigned a weight

$$
p_{i}(\text { total })-p_{i}\left(\left|M_{i}\right|\right)<p_{i}<p_{i}(\text { total })-p_{i}\left(\left|m_{i}\right|\right) .
$$

And a determining factor $f_{i}$ is "very unsupportable" if at most $[80 \%]$ of its indicators is not achieved. Thus its weight is $0<p_{i}<p_{i}($ total $)-p_{i}\left(\left|M_{i}\right|\right)$.

Then let's give the whole majority and half of each factors.
For this, the calculations are made according to their categories.

\subsection{Determining Factors Composed by Indicators "Without" Sub-Indicators}

For this first category, the calculation is easy. We simply use the formula below:

$$
\left\{\begin{array}{l}
\left|M_{i}\right|=\left|l_{i} * 80 \%\right| \\
\left|m_{i}\right|=\left|l_{i} * 50 \%\right|
\end{array}\right.
$$

As this category has only two determining factors (international trade $f_{2}$ and employment $f_{6}$ ). Here are the whole majority and half (cf. Table 2):

Table 2. Whole majority of determining factors "without" sub-indicators.

\begin{tabular}{llll}
\hline Determining factor & $\boldsymbol{l}_{\boldsymbol{i}}$ & $\left\lfloor\boldsymbol{M}_{\boldsymbol{i}}\right\rfloor$ & $\left\lfloor\boldsymbol{m}_{\boldsymbol{i}}\right\rfloor$ \\
\hline International Trade $f_{2}$ & 4 & 3 & 2 \\
Employment $f_{6}$ & 4 & 3 & 2 \\
\hline
\end{tabular}

Source: Author.

\subsection{Determining Factors Composed by Indicators "with" Sub-Indicators}

For the second category, the evaluation of the whole majority and half of each factor with sub-indicators is done in two steps:

$1^{s t}$ step: determination of whole majority and half of the sub-indicators of indicators.

This determination is similar to the previous case.

\begin{tabular}{|c|c|c|c|c|c|c|c|c|c|c|c|c|c|c|c|c|c|c|c|}
\hline \multirow[b]{2}{*}{ Indicator } & \multicolumn{3}{|c|}{ Agriculture } & \multicolumn{3}{|c|}{ Culture } & \multicolumn{5}{|c|}{ Education } & \multicolumn{3}{|c|}{ Industrialization } & \multicolumn{3}{|c|}{ Infrastructures } & \multicolumn{2}{|c|}{ Politics } \\
\hline & PO & OV & TE & CI & $\mathbf{E E}$ & ID & $\mathbf{B E}$ & SE & HE & SR & TP & PD & MP & CD & PI & DH & UB & IP & $\mathbf{P E}$ \\
\hline$\alpha_{j}$ & 3 & 2 & 2 & 3 & 5 & 3 & 4 & 2 & 2 & 3 & 2 & 2 & 3 & 4 & 4 & 2 & 3 & 6 & 3 \\
\hline$M_{\alpha_{j}}$ & 2 & 1 & 1 & 2 & 4 & 2 & 3 & 1 & 1 & 2 & 1 & 1 & 2 & 3 & 3 & 1 & 2 & 4 & 2 \\
\hline$m_{\alpha_{j}}$ & 1 & 1 & 1 & 1 & 2 & 1 & 2 & 1 & 1 & 1 & 1 & 1 & 1 & 2 & 2 & 1 & 1 & 3 & 1 \\
\hline
\end{tabular}

Table 3. Whole majority and half of the sub-indicators.

Source: Author.

$2^{\text {nd }}$ step: calculating the whole majority and half of the determining factors with the whole majority and half of its sub-indicators.

This calculation is obtained by using the following system

$$
\left\{\begin{array}{l}
\left|M_{i}\right|=\sum_{j=1}^{k}\left|M_{\propto_{j}}\right| \\
\left|m_{i}\right|=\sum_{j=1}^{k}\left|m_{\propto_{j}}\right|
\end{array} \text { where } k \in I \subset \mathbb{N}\right.
$$

Table 4. Whole majority and half of determining factors "without" sub-indicators.

\begin{tabular}{lll}
\hline Determining factor & $\left\lfloor\boldsymbol{M}_{\boldsymbol{i}}\right\rfloor$ & $\left\lfloor\boldsymbol{m}_{\boldsymbol{i}}\right\rfloor$ \\
\hline Agriculture & 4 & 3 \\
Culture & 8 & 4 \\
Education & 8 & 6 \\
Industrialization & 6 & 4 \\
Infrastructures & 6 & 4 \\
Politics & 6 & 4 \\
\hline
\end{tabular}

Source: Author.

\subsection{Determining Factors Composed by Indicators "with" and "Without" Sub-Indicators}

This time, we completely separate the indicators with and without sub-indicators. Therefore, the determining factors have two types of majority and half: whole majority and half of indicators without sub-indicators (resp. with sub-indicators). The calculation is then done in two steps:

$1^{\text {st }}$ step: determination of the whole majority and half of indicators without sub-indicators. We use the formula 6.1 used in the $1^{\text {st }}$ category.

$2^{\text {nd }}$ step: determination of the whole majority and half of the indicators with sub-indicators. The process is the same as in the $2^{\text {nd }}$ category. So here is the result.

Table 5. Whole majority and half of determining factors "with" and "without" sub-indicators.

\begin{tabular}{llll}
\hline Determining factor & $\boldsymbol{N}_{\boldsymbol{i}}$ & $\left\lfloor\boldsymbol{M}_{\boldsymbol{i}}\right\rfloor$ & $\left\lfloor\boldsymbol{m}_{\boldsymbol{i}}\right\rfloor$ \\
\hline Economy & 3 & 2 & 1 \\
Health & 3 & 2 & 1 \\
\hline
\end{tabular}

Source: Author. 
Table 6. Whole majority and half of indicators "with" sub-indicators of some determining factors.

\begin{tabular}{llll}
\hline Indicator & $\mathbf{N S}_{\mathbf{i}}$ & $\left\lfloor\boldsymbol{M}_{\mathbf{N S}_{\mathbf{i}}}\right\rfloor$ & $\left\lfloor\boldsymbol{m}_{\mathbf{N S}_{\mathbf{i}}}\right\rfloor$ \\
\hline Economy & 2 & 1 & 1 \\
SM & 2 & 2 & 1 \\
DO & 3 & 2 & 1 \\
Health & 3 & 2 & \\
DG & & & \\
\hline
\end{tabular}

Source: Author.

Then we will study the connection between determining factors.

\subsection{Connection Between Determining Factors}

Definition (28) Two or more determining factors are called "tied" if the supportability of one causes changes in the other. Two or more determining factors are "free" if the supportability of one has no effect on the other.

Proposition (29) If agriculture is supportable then there are significant improvements in the following determining factors: health, industrialization, economy, infrastructures, education and employment.

Proof. Suppose that agriculture of one country is not sustainable, then either production does not cover local consumption or the raw materials of industrialization are inadequate, or the country has to import its staple food. Thus the population is undernourished, and this affects public health and employment. It implies unsustainable industrialization, which in turn leads to the weakness of economy (due to the insufficiency of production in all areas) because without wealth created, there is no added value. But as the means to the agriculture deployment are underexploited, technical advancements are not essential. So scientific research is neglected. But the development and promotion of agriculture are based, in part, on the creation, construction and development of good infrastructures. Then they are neglected too. Finally, a sector that has a potential to create many jobs in the various activities that result from it will not be well exploited.

Proposition (30) If international trade is supportable then these determining factors are improved and boosted economy, industrialization, infrastructures, politics (external policy) and employment.

Proof. Suppose that international trade is neglected i.e. the country does not specialize neither in services nor in natural resources or in the international market. Also the trade balance is in deficit. The negative impact on the economy is then, the loss of means to earn foreign currency. In addition the State cannot pay for imports because they are more expensive than exports. This also affects the external policy because it has not the capacity to invest abroad. Moreover, industrialization is disadvantaged because it loses new markets for its productions. As different kinds of jobs are created upstream and downstream of this activity, this negligence will cause the opposite effect. Finally, as goods trade require their good circulation, infrastructures especially transport is imperative. But when one neglects international trade, then infrastructures transport are not necessary.

Proposition (31) If culture is supportable this leads to change politics (internal and external), economy, infrastructures, agriculture, industrialization, education, health and international trade.

Proof. Unspoiled culture and a strong ideology promote the application of a healthy and suitable policy, a skillful and strong economy, adapted infrastructures to the real needs of the country. Since all actions are done for the welfare, development, respect and benefits of the country and each citizen, thus agriculture and industrialization are undertake; education and health become national priorities. Finally, a strong culture in a country leads to the takeoff of the country by international trade. Because we consume more local products than imported ones. The local market is implicitly protected and the country can even tackle a foreign market.

Proposition (32) If economy is supportable then industrialization, trade, politics, infrastructures, education and culture are improved and have international visibility

Proof. Suppose that there is economic growth. This makes an optimum industrialization because of protectionism. An advantageous commercial exchange is produced by this industrialization, monetary stability and the opening of the economy not only allow the easy growth of national and international trades but at the same time it increases FDI. The accumulation of currency reserves and foreign currency involves the capacity to renovate, to maintain the proper infrastructures and why not to create new ones. This accumulation also stimulates big investments in education. Finally, it produces significant impacts on culture because a strong economy promotes conservation of cultural identity.

Proposition (33) If education is supportable, it allows culture, politics, economy, employment, agriculture, industrialization and infrastructures to be better and have international exposure.

Proof. Let's suppose we have a quality education. It first involves a very high enrollment rate that allows the transmission of good ideological values and cultural heritage from one generation to another to most children. Then, as many adults have a high level of education, politics and the economy are practiced skillfully, efficiently and thoughtfully. Mastering more environmental and natural resources are an important source of new jobs. Finally, the promotion of scientific research and technical advancements contribute to the development of agriculture, industrialization and infrastructures improvements.

Proposition (34) If employment is supportable so education, health, infrastructures and economy are improved.

Proof. Let's suppose there is growth in employment i.e. a non-significant unemployment, a remarkable decrease in underemployment, increase in purchasing power and living standards as well as increase of the number of taxpayers. So economic growth is pushed further by production and tax revenues increase. Each family can afford the cost of schooling and education for their children or even pay for good quality housing. All this leads to a good health condition of people. 
Remark (35) Industrialization here is the construction and creation of industries that respect international standards especially in terms of environmental and social aspects.

Proposition (36) If industrialization is supportable then there is change in employment, education, economy, infrastructures and international trade.

Proof. Suppose we have a strong industrialization that is to say both a very competitive local heavy industry compared to that of other countries and many diverse and varied industries. While new jobs are created upstream and downstream of this sector. In addition, the implantation of industries is also beneficial for the local region and the whole country due to the economic and social benefits including input of royalties, dividends and various taxes imposed by the State to manufacturers. Then if it goes well, production and added values increase, which promotes export. So the economy is growing. Finally, the technical and scientific advances and the knowledge required by industrialization make education a more powerful area and of infrastructures a good sector.

Proposition (37) Suppose that infrastructures are supportable. While the fields are gradually improving: agriculture, economy, employment, health and industrialization.

Proof. Suppose that infrastructures are not supportable i.e. there is deficiency of energy or communications infrastructures, or dilapidated infrastructures or the predominance of precarious housing or slums. This disadvantages not only the development of agriculture and industrialization but also economic growth. In addition, there is a risk of health problems and the incapacity to create new jobs.

Proposition (38) If the policy is not unsupportable education, infrastructures, industrialization, agriculture, international trade, culture and the economy are all improved and competitive.

Proof. Suppose that the policy is bad. This then leads to the inadequacy of the policy outlined by the government to the real needs of the country. So, education and infrastructures are neglected, the progress of the agricultural sector is delayed. In addition, the international trade is not mastered which causes a weak economy and dependence on foreign capital. It also weakens the national sovereignty, nonmanagement of aid and foreign debt and the considerable lack of direct investments abroad. So industrialization and local production are no longer protected from imported products and culture disappear gradually.

Proposition (39) If health is supportable then employment, education, agriculture and the economy are also advanced.

Proof. Healthy people are able to work and study better. In the same way agriculture produces more and this causes in turn economic growth.

\subsection{Calculation of Determining Factor Value}

Let be $f_{i}$ where $i \in\{1, \ldots, 10\}$ a determining factor.

Definition (40) The dependence coefficient $D C_{i}$ of $f_{i}$ is the number of determining factors which is linked by itself.

Definition (41) The value of determining factor $V\left(f_{i}\right)$ of $f_{i}$ is equaled to

$$
V\left(f_{i}\right)=10-D C_{i}-1
$$

Here is the table showing the dependence coefficient $D C_{i}$ and value of $f_{i}$, cf. Table 7 .

\section{Characterization}

First, there is the classification of determining factors in order of importance.

Definition (42)

- If $0<V\left(f_{i}\right)<3$, then the determining factor $f_{i}$ is "very important".

- If $0<V\left(f_{i}\right)<3$, thus $f_{i}$ is "important".

- When $V\left(f_{i}\right)>5$, so $f_{i}$ is "less important".

Table 7. Dependence coefficient and value of determining factors.

\begin{tabular}{lll}
\hline Determining factor & $\boldsymbol{D} \boldsymbol{C}_{\boldsymbol{i}}$ & $\boldsymbol{V}\left(\boldsymbol{f}_{\boldsymbol{i}}\right)$ \\
\hline Agriculture $\left(f_{1}\right)$ & 6 & 3 \\
International Trade $\left(f_{2}\right)$ & 4 & 5 \\
Culture $\left(f_{3}\right)$ & 8 & 1 \\
Economy $\left(f_{4}\right)$ & 6 & 3 \\
Education $\left(f_{5}\right)$ & 7 & 2 \\
Employment $\left(\mathrm{f}_{6}\right)$ & 4 & 5 \\
Industrialization $\left(f_{7}\right)$ & 5 & 4 \\
Infrastructures $\left(f_{8}\right)$ & 5 & 4 \\
Politics $\left(f_{9}\right)$ & 7 & 2 \\
Health $\left(f_{10}\right)$ & 4 & 5 \\
\hline
\end{tabular}

Source: Author.

Proposition (43) (Ranking of determining factors). We can classify the determining factors as follows (cf. Table 8):

Table 8. Ranking of determining factors according to their rank.

\begin{tabular}{ll}
\hline Rank & Determining factor \\
\hline \multicolumn{2}{l}{ Very Important factors } \\
1 & Education \\
2 & Culture \\
3 & Politics \\
Important factors & \\
4 & Economy \\
5 & Agriculture \\
6 & Industrialization \\
7 & Infrastructures \\
Less factors & \\
8 & Health \\
9 & Employment \\
10 & International trade \\
\hline
\end{tabular}

Source: Author.

Proof. Immediately according to the Definition (42) and the Table 7.

Then we will establish relation between link and state of determining factors.

Proposition (44) If $\left\{f_{i}\right\}, i \in\{1, \ldots, 10\}$ is supportable (resp. supportable, unsupportable, very unsupportable), while there are direct impacts with other determining factor interacting with it.

Proof. This follows by Proofs (or negation of proofs) of Propositions (29), (30), (31), (32), (33), (34), (36), (37), (38), (39). 
Remark (43) When the determining factor is very supportable (resp. supportable), thus there is direct positive impacts $^{2}$ on the determining factors that interact with it. And when it is very unsupportable (resp. unsupportable), this condition causes direct negative impacts ${ }^{3}$ on the determining factors related to it.

We'll see the following definitions and study different aspects and dimensions of development (resp. nondevelopment). Then we will create a new index to measure a country's development.

Definition (45) Grouping determining factors is the process of bringing together in one set determining factors that measure the same pane.

Definition (46) The human component is a set of determining factors that directly affects humans.

Proposition (47) The human component has four (4) elements that are called human determining factors. They are culture $H_{1}$, education $H_{2}$, employment $H_{3}$ and health $H_{4}$. They are grouped together in a set noted $H$.

Proof. Consider a person. We know that he is composed of body, knowledge and soul. For the body, it needs to be healthy, fed, clothed and housed. Now they require money, and usually for everyone, money is obtained through salary and income, and therefore from his employment. As for knowledge, it is shaped by education and also culture. Speaking of soul, it is based on beliefs and as such by culture. Thus the human component consists of four key factors.

Definition (48) The economical component is a set of determining factors that indicate human activities that are directly related to the production, consumption and investment.

Proposition (49) The economic component consists of five (5) elements called economical determining factor namely agriculture $E_{1}$, international trade $E_{2}$, economy $E_{3}$, industrialization $E_{4}$, infrastructures $E_{5}$. They form a set noted $E$.

Proof. Economic activities are viewed with production, trade and profits. For production, it comes from agriculture and industry. We notice that production requires infrastructures to make the good circulation of production. For exchanges, they are practiced at local and global (regional, continental and international) levels. In other words, local and international trades. For profits, the corresponding factor is economy.

NB: The production, trade and profits are linked, interdependent and form a cycle. Indeed, one produces in order to exchange after. Without benefit, exchanges are useless. From profits we can again invest and increase the production.

Definition (50) The political component is a set of determining factors which focuses on social, economic and environmental actions. It takes also account of the relationship between a country and another.

Proposition (51) The political determining factor is politics $f_{9}$.

Proof. Among the ten key factors and using a process of elimination, politics is the only determining factor that takes into account the actions carried on within and outside one country.

Corollary (52) The political component is $\mathrm{f}_{9}$.

Proof. Immediately by the Proposition (51)

Proposition (53) (Development Components). All development (resp. nondevelopment) is characterized by human, economic and political components.

Proof. Immediately by Propositions (51), (49) and Corollary (52).

Theorem (54) The essence of the pair developmentnondevelopment is the human component.

Proof. First we find that the weight of the human component is $P(H)=\sum_{k=1}^{4} H_{k}=34$. In addition we have $p(P)<p(H)$ and $p(E)<p(H)$. So the human element is the weightiest components. Thus the economic and political aspects are entirely based on the human aspect. Indeed, economic and politics practices are from men. Therefore, they are the main actors and beneficiaries of development.

Corollary (55) Without "culture" and "education" there is no development for one country.

Proof. On the one hand, suppose $f_{3}$ and $f_{5}$ are unsupportable. Then according to Proposition (31), $f_{1}, f_{2}, f_{4}, f_{5}, f_{7}, f_{8}, f_{9}$ and $f_{10}$ are linked with $f_{3}$ and by Proposition (33); $f_{1}, f_{3}, f_{4}, f_{6}, f_{7}, f_{8}$ and $f_{9}$ are linked with $f_{5}$. So from all these determining factors we obtain the remaining other factors. Using Proposition (44), we conclude that the state of these two factors will have negative impacts on others. So development process would not start.

On the other hand, we have $\sum_{i=1}^{10} D C_{i} / 10=57 / 10$ which is the sum of dependence factors. Yet $D C_{3}+D C_{5}=15$. So the sum of culture and education is $26,3 \%$. Thus according to the $20 / 80$ of Pareto law, to undertake the process of development we must work on the $20 \%$ of elements which make $80 \%$ of results. Therefore the pillars of development are culture and education.

Remark (56) We notice that the economic component is a direction vector while the politics is a catalyst for development.

Definition (57). - The development of a country requires the simultaneous supportability of the human, economic and political components.

- The nondevelopment of a country is reflected as unsupportability of these three components.

Remark (58) We choose here the adjective "nondevelopment" to denote any countries that are not developed namely poor, underdeveloped, in crisis,.... Because if we have used the adjective "underdeveloped", some people will say that it concerns only the former colonies alone. If we have used the term "poor", others will point out that only countries with low income per capita are concerned. As for "in crisis" it refers to political or financial instable countries.

Definition (59) - The development-nondevelopment index $I$ is an index that measures a quality and level of development of one country compared to another.

- The index $I$ is obtained by

At time $t \in \mathbb{N}^{*}$ 


$$
I(t)=\sum_{k=1}^{4} p\left(H_{k}\right)(t)+p(P)(t)+\sum_{k=1}^{5} p\left(E_{l}\right)(t)
$$

Properties

- The quality of country development refers to its character whether it is human or economic or both.

- From the index I, we can make and set two world rankings by the quality and level of development of any country. We can also simply calculate only the HDI, economic growth, cultural development,.... It is the only index that covers multiple existing development indicators.

- It also shows that the development (resp. nondevelopment) is multidimensional.

Proposition (60) Depending on the value of the development/nondevelopment index, different categories of country are brought out according to the development degree

$1^{\text {st }}$ category: If $\mathrm{M}$ is supportable (resp. unsupportable) so we have a "human" development (nondevelopment).

$2^{\text {nd }}$ category: If $E$ is supportable (resp. unsupportable) thus we get an "economic" development (resp. nondevelopment).

$3^{\text {rd }}$ category: If $\mathrm{M}$ and $\mathrm{E}$ are both supportable (resp. unsupportable) so we obtain a "human and economic" development (resp. nondevelopment).

Proof. For the $1^{\text {st }}$ category, assume that $M$ is very supportable. While the human aspect is tolerable and therefore all human determining factors are all very supportable. And $P(H)$ is quite high. Analogously we prove the other two categories.

Remark (61) A country is highly developed (resp. less developed) if the three components of development are simultaneously very supportable (resp. very unsupportable).

Proposition (62) We have the following development ranking level of country: (a). If all $H, P, E$ are supportable thus the country is "highly developed".

(b). If all H, P,E are supportable so the country is "developed".

(c). If all H, P, E are unsupportable thus the country is "nondeveloped".

(d). If all $H, P, E$ are unsupportable so the country is "less developed".

Proof. Just use the Definition (57) and Remark (61).

Theorem (63) The economic component depends on the human component.

Proof. The determining factors that make up the economic component are agriculture $f_{1}$, international trade $f_{2}$, economy $f_{4}$, industrialization $f_{7}$ and infrastructures $f_{8}$. And we see that the activities arising from $f_{1}, f_{2}, f_{4}$ and $f_{7}$ depend totally on know-how and knowledge. Yet these two things are acquired through education and culture. And for infrastructures, they are created, built and shaped by man. Suppose that each dwelling is occupied by a household. The home quality depends on the amount of revenues. As employment provides the revenues, the quality of housing is based on revenues. Using Propositions (29), (30), (32), (36), and (37) we get the result.

Theorem (64) The human component is based on the economic one.

Proof. Any social progress depends on man. It is known that the latter needs food, study, work, be healthy, leisure and cultural identity. Now these basic needs are the fruits of agriculture, industrialization, trade and/or infrastructures which are the elements of the economic component.

Theorem (65) (Development law). The nondevelopment of one country produces the development of the others.

Proof. Suppose our world is placed in a space where each country belonging to it, has their own determining factors. We assume that in this space, natural resources are distributed randomly; and we share one and only one global market and each country has their own culture.

Consider two countries $P_{a}$ and $P_{b}$ are taken together in this space as developed and undeveloped with their respective determining factors $f_{i}^{a}$ such that $i \in\{1, \ldots, 10\}$ and $f_{j}^{b}$ with $j \in\{1, \ldots, 10\}$. Let $I_{a}$ and $I_{b}$ development/ nondevelopment index respectively to $P_{a}$ and $P_{b}$.

First by Proposition (62), $P_{a}$ developed leads the supportability of human, economic and political components, especially $f_{2}^{a}, f_{3}^{a}, f_{4}^{a}$ and $f_{7}^{a}$. We know that the supportability of industrialization $f_{7}^{a}$ requires plenty of raw materials. On the one hand, this makes $P_{a}$ to specialize in various industrial products. Pushing by these different specializations, international trade $f_{2}^{a}$ becomes dynamic, competitive and lucrative. Therefore $P_{a}$ has a prominent place in the global market. However the increase in production promotes the increase of the added values produced. Thus, the economy $f_{4}^{a}$ progress significantly and accumulate reserves. On the other hand, this supportability allows $P_{a}$ to cover all or most of its industrial needs. Thus, it does not need to import finished goods, or in small volume in the case it imports. Yet in both cases, the local market is completely monopolized by local products. So the latter are more consumed than foreign products. This implies that the incursion and the impact of foreign culture through imports become minimal, and allows the conservation and enhancement of culture $f_{3}^{a}$.

Second, as $P_{b}$ is a nondeveloped country thus all development components, such as industrialization $f_{7}^{b}$, international trade $f_{2}^{b}$, economy $f_{2}^{b}$ and culture $f_{3}^{b}$ are unsupportable. Let's assume that the unsupportability of $f_{7}^{b}$ is due to the under exploitation and bad use of raw materials. Then, developed countries at the growing search for raw materials and natural resources for the long term development of industrialization can take advantage of this situation. Indeed, two cases may occur:

$1^{\text {st }}$ case: If $P_{a}$ is a country that has no natural resources it will directly exploit those of $P_{b}$ to get raw materials. In addition, $P_{a}$ promotes the export of raw materials of $P_{b}$ by its insertion in the world market.

$2^{\text {nd }}$ case: If $P_{a}$ is a country with natural resources but it still needs more for various reasons either to increase the amount of its production or to expand new industries, it will draw them elsewhere especially in countries such as $P_{b}$ which does not know what to do with. Then $P_{a}$ will operate in place of directly or indirectly (through international trade including the import of raw materials at low price). In both cases, industrialization $f_{7}^{b}$ does not take off. Indeed, if $P_{b}$ does not known how to exploit its natural resources, countries such as $P_{a}$ will use in its 
place. However, these natural resources are not renewable. So $P_{b}$ will know later a shortage of raw materials that will result from failure of its industrialization $f_{7}^{b}$. And this underindustrialization of $P_{b}$ becomes beneficial to the dynamism of industrialization in other developed countries $P_{a}$. The consequences of this on $P_{b}$ are, first, since $P_{b}$ cannot cover industrial needs of its population it will resort to the importation of these products. Therefore it loses its local market. And in addition it must find ways to facilitate and pay for imports needed. This implies increased imports accompanied by the abandonment of protectionist measures and a stifled economy through the export of primary products at low cost, the increasing import of finished products at very high prices and considerable lack of foreign currency. As the world market is unique, $P_{a}$ will conquer the market share of $P_{b}$ So it loses market share while $P_{a}$ wins in return.

And besides its industries have provided opportunities to sell its production. This allows $P_{a}$ to have a thriving economy and a profitable trade in contrast to the situation of $P_{b}$. Indeed the trade balance deficit is definitely accompanied by the deterioration of its trade. These will result in an indebted economy that cannot accumulate the necessary reserves to face its many imports. Thus, undoubtedly $P_{b}$ occupies a marginal position in the global market. Then, considering that $P_{b}$ considerably imports manufactured goods. So protectionism is set aside to give way to free trade. Therefore the little elaborate productions (due to technical shortages and knowledge) and local small company (with a small capital) are not protected against imported products (highend, very elaborate and sophisticated) and large foreign conglomerates (with a very large amount of capital) from $P_{a}$. So imported products will be increasingly consumed compared to local products. Now all products of $P_{a}$ carry with them a part of his culture. Then, the culture of $P_{b}$ is devalued and is gradually destroyed in favor of the culture of $P_{a}$. Taking into account what we have seen above, the underindustrialization of $P_{b}$ is inevitably linked to the industrialization of $P_{a}$, the deteriorating trade at international level of $P_{b}$ is the direct result of the specialization of $P_{a}$ in the world market, the disappearance of culture of $P_{b}$ leads to the adoption of the culture of $P_{a}$. In terms of determining factors, $f_{2}^{b}$ is unsupportable to make $f_{7}^{a}$ supportable; $f_{3}^{b}$ is intolerable to make $f_{3}^{a}$ be supportable; $f_{4}^{b}$ is very unsupportable for the supportability of $f_{4}^{a}$ and unsupportability of $f_{7}^{b}$ generates supportability of $f_{7}^{a}$.

Nevertheless with $f_{2}^{b}, f_{3}^{b}, f_{4}^{b}$ and $f_{7}^{b}$ remaining determining factors are all obtained. The unsupportability of these four determining factors cause negative impacts on others according to Proposition (44) because most of determining factors interact with them will be affected more than twice their state. So from these four determining factors, all others are unsupportable. Thus the nondevelopment of $P_{b}$ is the result of development of $P_{a}$.

Remark (66) This development law includes the original Marxist theory that says "Underdevelopment of the one is the product of the development of the others". Indeed all underdeveloped countries are poor but all poor countries are not automatically underdeveloped.

Example.

(a). Let $P_{1}$ be a country which occupies a prominent place in international trade.

Thus there is another country $P_{2}$ undergoing the following consequences: either its international market part will be reduced or it loses a significant part of its local market part.

(b). If a country $P_{3}$ completes its green revolution, then its local food consumption will be covered. Thus it will reach food security and would not have to import food. Yet there will be country $P_{4}$ losing a potential market which will reduce its export and create significant consequences on its economy and foreign trade.

Remark (67) But the reverse of Theorem (65) is not always true, i.e. the development of one country does not necessarily mean the poverty of others. Just see that even if China is developing it does not prevent India from developing in its turn.

Corollary (68) The poverty of one products development of others.

Proof. Since poverty is a special case of nondevelopment then using Theorem (65) we have the result.

\section{Conclusion}

To conclude, we can say that the determining factors are very interesting tools to study simultaneously development and nondevelopment. They inform us about the dimensions, the components and the pillar of both development and nondevelopment. These studies also show the intrinsic link between development and nondevelopment. Finally we can say that to make a nondeveloped country to become a developed one, it is important to choose politics which respects the human and economic components.

\section{Appendix}

Development exhaustive list of classification.

Table A1. Development character of a country.

\begin{tabular}{lll}
\hline Indicator & State & Value of weights \\
\hline$H, P$ very supportable & & \\
$H, P E$ & very supportable & $23<p(H)<34$ and $6<p(P)<9$ \\
& supportable & $16<p(E)<24$ \\
$H, P E$ & very supportable & $23<p(H)<34$ and $<p(P)<9$ \\
& unsupportable & $12<p(E)<20$ \\
$H, P E$ & very supportable & $23<p(H)<34$ and $6<p(P)<9$ \\
$H, P$ supportable & very unsupportable & $0<p(E)<12$ \\
\hline
\end{tabular}




\begin{tabular}{|c|c|c|}
\hline Indicator & State & Value of weights \\
\hline \multirow{2}{*}{$H, P E$} & supportable & $14<p(H)<23$ and $4<p(P)<6$ \\
\hline & very supportable & $24<p(E)<36$ \\
\hline$H, P E$ & $\begin{array}{l}\text { supportable } \\
\text { unsupportable }\end{array}$ & $\begin{array}{l}14<p(H)<23 \text { and } 4<p(P)<6 \\
12<p(E)<20\end{array}$ \\
\hline$H, P E$ & supportable & $14<p(H)<23$ and $4<p(P)<6$ \\
\hline \multicolumn{3}{|c|}{$H, P$ unsupportable } \\
\hline$H, P E$ & $\begin{array}{l}\text { Unsupportable } \\
\text { very supportable }\end{array}$ & $\begin{array}{l}11<p(H)<20 \text { and } 2<p(P)<3 \\
24<p(E)<36\end{array}$ \\
\hline$H, P E$ & $\begin{array}{l}\text { unsupportable } \\
\text { supportable }\end{array}$ & $\begin{array}{l}11<p(H)<20 \text { and } 2<p(P)<3 \\
16<p(E)<24\end{array}$ \\
\hline$H, P E$ & $\begin{array}{l}\text { Unsupportable } \\
\text { Very unsupportable }\end{array}$ & $\begin{array}{l}11<p(H)<20 \text { and } 2<p(P)<3 \\
0<p(E)<12\end{array}$ \\
\hline \multicolumn{3}{|c|}{$H, P$ very unsupportable } \\
\hline$H, P E$ & $\begin{array}{l}\text { Very unsupportable } \\
\text { very supportable }\end{array}$ & $\begin{array}{l}0<p(H)<1 \text { and } 0<p(P)<2 \\
24<p(E)<36\end{array}$ \\
\hline$H, P E$ & $\begin{array}{l}\text { Very unsupportable } \\
\text { supportable }\end{array}$ & $\begin{array}{l}0<p(H)<11 \text { and } 0<p(P)<2 \\
16<p E<24\end{array}$ \\
\hline$H, P E$ & $\begin{array}{l}\text { Very unsupportable } \\
\text { unsupportable }\end{array}$ & $\begin{array}{l}0<p(H)<11 \text { and } 0<p(P)<2 \\
12<p(E)<20\end{array}$ \\
\hline \multicolumn{3}{|c|}{$E, P$ very supportable } \\
\hline$E, P H$ & $\begin{array}{l}\text { very supportable } \\
\text { supportable }\end{array}$ & $\begin{array}{l}24<p(E)<36 \text { and } 6<p(P)<9 \\
14<p(H)<23\end{array}$ \\
\hline$E, P H$ & $\begin{array}{l}\text { very supportable } \\
\text { unsupportable }\end{array}$ & $\begin{array}{l}24<p(E)<36 \text { and } 6<p(P)<9 \\
11<p(H)<20\end{array}$ \\
\hline$E, P H$ & $\begin{array}{l}\text { very supportable } \\
\text { very unsupportable }\end{array}$ & $\begin{array}{l}24<p(E)<36 \text { and } 6<p(P)<9 \\
0<p(H)<11\end{array}$ \\
\hline \multicolumn{3}{|c|}{$E, P$ supportable } \\
\hline$E, P H$ & $\begin{array}{l}\text { Supportable } \\
\text { very supportable }\end{array}$ & $\begin{array}{l}16<p(E)<24 \text { and } 4<p(P)<6 \\
23<p(H)<34\end{array}$ \\
\hline$E, P H$ & $\begin{array}{l}\text { supportable } \\
\text { unsupportable }\end{array}$ & $\begin{array}{l}16<p(E)<24 \text { and } 4<p(P)<6 \\
11<p(H)<20\end{array}$ \\
\hline$E, P H$ & $\begin{array}{l}\text { supportable } \\
\text { very unsupportable }\end{array}$ & $\begin{array}{l}16<p(E)<24 \text { and } 4<p(P)<6 \\
0<p(H)<11\end{array}$ \\
\hline \multicolumn{3}{|c|}{$E, P$ unsupportable } \\
\hline$E, P H$ & $\begin{array}{l}\text { unsupportable } \\
\text { very supportable }\end{array}$ & $\begin{array}{l}12<p(E) \leq 20 \text { and } 2<p(P) \leq 3 \\
23<p(H) \leq 34\end{array}$ \\
\hline$E, P H$ & $\begin{array}{l}\text { unsupportable } \\
\text { supportable }\end{array}$ & $\begin{array}{l}12<p(E) \leq 20 \text { and } 2<p(P) \leq 3 \\
14<p(H) \leq 23\end{array}$ \\
\hline$E, P H$ & $\begin{array}{l}\text { unsupportable } \\
\text { Very unsupportable }\end{array}$ & $\begin{array}{l}12<p(E) \leq 20 \text { and } 2<p(P) \leq 3 \\
0<p(H) \leq 11\end{array}$ \\
\hline \multicolumn{3}{|c|}{$E, P$ very unsupportable } \\
\hline$E, P H$ & $\begin{array}{l}\text { Very unsupportable } \\
\text { very supportable }\end{array}$ & $\begin{array}{l}0<p(E) \leq 12 \text { and } 0<p(P) \leq 2 \\
23<p(H) \leq 34\end{array}$ \\
\hline$E, P H$ & $\begin{array}{l}\text { Very unsupportable } \\
\text { supportable }\end{array}$ & $\begin{array}{l}0<p(E) \leq 12 \text { and } 0<p(P) \leq 2 \\
14<p(H) \leq 23\end{array}$ \\
\hline$E, P H$ & $\begin{array}{l}\text { Very unsupportable } \\
\text { unsupportable }\end{array}$ & $\begin{array}{l}0<p(E) \leq 12 \text { and } 0<p(P) \leq 2 \\
11<p(H) \leq 20\end{array}$ \\
\hline$H, E, P$ & very supportable & $23<p(H) \leq 34,24<p(E) \leq 36$ and $6<p(P) \leq 9$ \\
\hline$H, E, P$ & supportable & $14<p(H) \leq 23,16<p(E) \leq 24$ and $4<p(P) \leq 6$ \\
\hline$H, E, P$ & unsupportable & $11<p(H) \leq 20,12<p(E) \leq 20$ and $2<p(P) \leq 3$ \\
\hline$H, E, P$ & very unsupportable & $0<p(H) \leq 11,0<p(E) \leq 12$ and $0<p(P) \leq 2$ \\
\hline
\end{tabular}

\section{References}

[1] OCDE/CAD, Coopération pour le développement, $O C D E$ (1994), Paris.

[2] Rapport sur le Développement Humain 2011, Notes techniques, (2011).

[3] Rapport de la Commission du Sud, Défis au Sud, Economica (1990), 10-11.

[4] S. Amin, Le développement inégal. Essai sur les formations sociales du capitalisme périphérique. Minuit-Date: 1973365pp-In8-Broche- (1973).

[5] M. Bastid, La Chine après la révolution culturelle, Politique étrangère 1 (1972).

[6] C. Borell, Lecture notes in measure theory. (2006).

[7] A. Bouziad et J. Calbrix, Théorie de la Mesure et de l'Intégration, Université de Rouen (1993).

[8] A. Brawand, Sous-développement et nouvel ordre économique international, CIHEAM (1976), 30-39. 
[9] H. B. Chenery, The Process of Industrialization. In Structural Change and Development Policy, New York: Oxford Press (1979).

[10] A. Deardoff, Deardorffs' Glossary of International Economics, (2016), http: //www-personal.umich.edu/ alandear/glossary/.

[11] A. Delers et I. Van Steenkiste, La règle des 80/20 ou la loi de Pareto: Comment mieux s'organiser au quotidien ?, (2014), www.Amazon.fr.

[12] P. Deubel, Analyse économique et historique des sociétés contemporaines, Pearson Education France (2008).

[13] Jean-Raphaël et Chaponniere, Taïwan, un parcours sans faute, Matériaux pour l'histoire de notre temps number 45 (1997), doi: 10.3406/mat.1997.403066, 24-29.

[14] F. Hatem et D. Malpede, Le développement humain: genèse et perspective d'un concept, Economie Prospective Internationale number 49 (1992).

[15] M. Gaye, Afrique: Abandonner les solutions occidentales et repenser le développement autrement, Edilivre (2014), 120.

[16] L. Giovanni, Impacts des politiques sur la pauvreté - Définition de la pauvreté, $F A O$ (2006), www.fao.org/tc/easypol.

[17] Gro Harlem Brundtland; Commission mondiale sur l'environnement et le développement, Notre avenir à tous. Rapport Bruntland, Genève: La Commission, 1987 (1987).

[18] J. Cohen-Setton, A. Lallour, G. Faye et S. Pépin-Lehalleur, LePays pauvres: Quelle aide pour quel développement ?, (2006).

[19] S. Prybyla Jan, L'économie de la République Populaire de Chine: bilan de 25 années, Revue d'études comparatives EstOuest 8 number 4 (1977), 75-116.
[20] P. Judet, La Chine monte en puissance, Tiers-Monde 37 number 147 (1996).

[21] R. Koch, Le principe 80/20 faire plus avec moins, (2007), www.Amazon.fr.

[22] Y. Lacoste, Le concept de sous-développement et la Géographie, Annales de Géographie 76 number 418 (1967), doi: 10.3406/geo.1967.15064.

[23] J. R. Legouté, Définir le développement: historique et dimension d'un concept plurivoque, Université du Québec à Montréal (2001).

[24] F. Perroux, Qu'est-ce que le développement ?, Etudes (1961), 16.

[25] F. Perroux, L'économie du XXème siècle, Presses Universitaires de France, Paris (1964).

[26] A. Richiter et O. Liliana, Théories économiques du sousdéveloppement et les stratégies de leur élimination, (2007), 177-180.

[27] W. W. Rostow, Les étapes de la croissance économique. Un manifeste non communisme, Economica (1997), 3ème édition.

[28] Ch. Sautter, Croissance et stratégie internationale du Japon, Economie et statistique 97 (1978), doi: 10.3406/estat.1978.3087, 43-56.

[29] A. Sen, Development as Freedom, A. K. Knofp (2000), New York, 4.

[30] A. Serra, Antonio Serra and the Economics of Good Government, Palgrave Macmillan UK (2016), doi: $10.1057 / 9781137539960$.

[31] M. Troyanov, Mesures et Intégration, EPFL (2008). 